\title{
Effect of Hot Rolling on the Thermomechanical Properties of a Superelastic Cu-Al-Be-Cr Alloy
}

\author{
Gemierson Valois da Mota Candido ${ }^{a}$, Danniel Ferreira de Oliveira ${ }^{b *}$ (D), Ieverton Caiandre Andrade Brito ${ }^{b}$, \\ Rafael Evaristo Caluête ${ }^{c}$, Breno Henrique da Silva Andrade ${ }^{b}$, Danielle Guedes de Lima Cavalcante ${ }^{a, b}$ \\ aniversidade Federal da Paraíba, Programa de Pós-Graduação em Engenharia Mecânica, \\ João Pessoa, PB, Brasil, \\ ${ }^{b}$ Universidade Federal da Paraíba, Departamento de Engenharia de Materiais, João Pessoa, PB, Brasil \\ ${ }^{c}$ Universidade Federal da Paraíba, Departamento de Engenharia de Mecânica, João Pessoa, PB, Brasil
}

Received: September 27, 2019; Accepted: January 10, 2020.

\begin{abstract}
Shape memory alloys are generally produced by casting processes and are subsequently homogenized. However, to obtain semifinished products on an industrial scale, the ingots from the casting process must be hot worked. In particular, final bar and sheet products can be obtained by hot rolling process. During intense hot work, surface oxidation of the material and microstructural changes may cause modifications to its original thermomechanical properties. In this sense, the present work aimed to study the correlation of the superelastic behavior in a $\mathrm{Cu}-\mathrm{Al}-\mathrm{Be}-\mathrm{Cr}$ alloy before and after subjecting it to the hot rolling thermomechanical process. Abnormal grain growth was observed for a hot rolled sample with $30 \%$ reduction in initial alloy thickness. This abnormal growth in relation to non-rolled alloy caused an increase in phase transformation temperatures, a reduction in residual strain, a reduction in induction stress and an increase in alloy superelasticity.
\end{abstract}

Keywords: Abnormal grain growth, superelasticity, hot rolling.

\section{Introduction}

$\mathrm{Cu}-\mathrm{Al}$-Be system polycrystalline shape memory alloys (SMAs), modified with inoculant addition, have good shape memory and superelasticity properties, with a lower processing cost than conventional NiTi system SMAs, making them, attractive for technological applications ${ }^{1-5}$. In addition, $\mathrm{Cu}-\mathrm{Al}-\mathrm{Be} \mathrm{SMAs}$ can be modified for use at low temperatures. For example, the addition of only $0.1 \%$ beryllium $(\mathrm{Be})$ by weight is required for a phase transformation temperature reduction of these alloys by approximately $100{ }^{\circ} \mathrm{C}^{6}$. They have stable $\beta$ or austenitic phases and, when subjected to high temperatures, tend to stabilize the $\beta$ phase at room temperature through rapid cooling or quenching ${ }^{7}$.

Araya et al. ${ }^{8}$ studied the properties of the superelastic $\mathrm{Cu}-11.8 \% \mathrm{Al}-0.5 \%$ Be SMA alloy at room temperature to evaluate its application in seismic resistance projects. For this work, wires previously heated for different periods of time were produced to evaluate the effect of grain size. According to the authors, the increase in grain size led to a gain in equivalent damping, a reduction in direct transformation and final stresses.

The hot working process of SMA alloy ingots previously obtained by casting and further homogenization may be detrimental to the compositional stability and thermo-mechanical properties of the alloys. This is due to the intense oxidation and microstructural changes due to the high temperatures required for the process, especially in hot rolling 9 . Several studies seek to remedy or minimize this inconvenience.

Narendranath et al. ${ }^{10}$ studied the effects of different aging temperature treatments after hot rolling on martensitic phase transformation behavior and mechanical behavior of $\mathrm{NiTi}$

*email: dannieldeoliveira@gmail.com shape memory alloys. In their results they concluded that the stress induced martensite is more stable in relation to the thermal martensite. According to them, this is due to the change in the morphology of variant accommodation, from the self-accommodation of thermal martensite to the oriented state of tension-induced martensite. Superelasticity, associated with stress-induced martensitic transformation, increases with aging temperature gain $\left(350^{\circ} \mathrm{C}-550^{\circ} \mathrm{C}\right)$. This is associated with increased $\mathrm{Ti}_{3} \mathrm{Ni}_{4}$ and consequently network distortions.

Liu et al. ${ }^{11}$ investigated the effects of lamination and heat treatment on the CuAlMn shape memory alloy microstructure and superelasticity. These alloys were processed via unidirectional solidification, followed by rolling and heat treatment. The alloy showed high workability and good superelasticity through hot rolling control. The alloy reached a reduction of $80 \%$ in the first pass, maintaining columnar grain structure. After two passes, followed by annealing at $800{ }^{\circ} \mathrm{C}$, the superelastic deformation of the alloy reached $5.9 \%$, although it recrystallized. This same alloy, cold rolled at room temperature, showed a reduction rate of around $50 \sim 70 \%$, maintaining a two-phase columnar grain microstructure $\left(\beta_{1}+\alpha\right)$. Due to the precipitation of the $\alpha$ phase and the high annealing temperature, the grains may undergo abnormal growth, with diameters ranging from hundreds $\mu \mathrm{m}$ to more than $1 \mathrm{~cm}$ in diameter. The abnormal rate of grain growth is higher than that of the common polycrystalline alloy, and its superelastic deformation can reach about $7 \%$.

In this sense, the main objective of this study is to determine the influence of hot rolling (HR) on the mechanical properties, on transformation temperatures and on superelasticity of a $\mathrm{Cu}-\mathrm{Al}-\mathrm{Be}-\mathrm{Cr}$ alloy. 


\section{Materials and Methods}

The alloy with a nominal composition of $\mathrm{Cu}$ 11.8Al-0.6Be-0.3Cr (\% by weight) was melted in an uncontrolled JUNG muffle furnace in a graphite crucible in an approximate amount of $700 \mathrm{~g}$ and cast in a rectangular section mold with $120 \mathrm{~mm}$ long x $22 \mathrm{~mm}$ wide and $40 \mathrm{~mm}$ high. The obtained ingot was homogenized at $850{ }^{\circ} \mathrm{C}$ for 12 hours to improve dissolution of the alloying elements.

After homogenization the ingot was sectioned into three samples: two with $10 \mathrm{~mm}$ and one with $15 \mathrm{~mm}$ thick by wire EDM. The sample measuring $15 \mathrm{~mm}$ thickness was then subjected to the hot rolling (HR) process to reduce its thickness to $1.5 \mathrm{~mm}$ (this sample was designated $100 \%$ HR). The with $10 \mathrm{~mm}$ of thickness sample was hot rolled to a final thickness of $9.7 \mathrm{~mm}$ (this sample was designated $30 \% \mathrm{HR}$ ). The other $10 \mathrm{~mm}$ thickness sample was non-hot rolled and was designated to $0 \% \mathrm{HR}$.

Figure 1 shows the specimens for mechanical tests, for the samples with and without laminate, that were made by wire erosion. After preparation, the specimens were heated at $850^{\circ} \mathrm{C}$ for $30 \mathrm{~min}$ and then quenched with water to room temperature to obtain the shape memory effect.

To reveal the phases between which the alloy is studied, the specimens were prepared for metallographic analysis using a Carl Zeiss microscope, model Axiotech 30 at room temperature for structural characterization, allowing the visualization of the size of the alloy grain in each sample, as well as the recording of their images through the software Shortcut to Analysis.

Superelasticity tests were performed on a Shimadzu $50 \mathrm{kN}$-EHF servomotor test machine equipped with a heating and cooling chamber. The test jaws are designed to accommodate the sample heads and thus avoid any possibility of slipping during their execution.

Transformation temperatures were investigated by Differential Scanning Calorimetry using a Shimadzu DSC-60. The samples were heated and cooled at a rate of $10{ }^{\circ} \mathrm{C} / \mathrm{min}$ under a nitrogen atmosphere with constant flow with a rate of $50 \mathrm{ml} / \mathrm{min}$.

\section{Results and Discussion}

The grain size in $\mathrm{Cu}$-based shape memory alloys significantly influences their mechanical properties. It means that the alloy with larger grain size can achieve higher superelastic

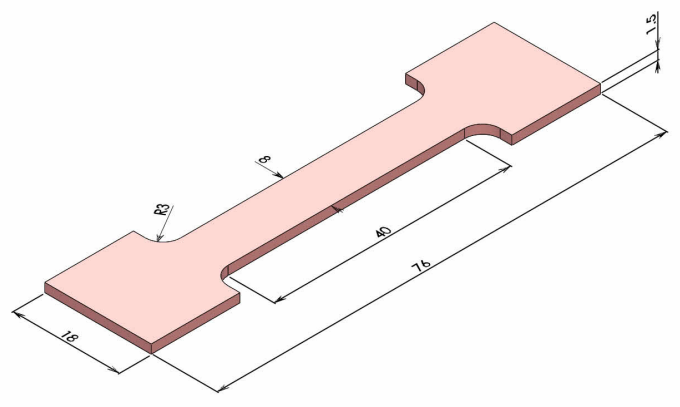

Figure 1 - Schematic drawing of the specimen via electroerosion. Dimensions in (mm). stress $^{12-14}$. Figure 2 shows the macrostructures of the rolled and non-rolled $\mathrm{Cu}-11.8 \mathrm{Al}-0.6 \mathrm{Be}-0.3 \mathrm{Cr}$ specimens. It was found that the non-hot rolled samples Figure 2a have very similar grains in relation to the samples that went through the hot rolling process Figure $2 b$, especially the sample of Figure 2c which showed an abnormal grain growth. This abnormal grain growth has been observed in SMAs undergoing cyclic heat treatments ${ }^{15,16}$.

According to Kusama et al. ${ }^{17}$ The mechanism responsible for abnormal grain growth is the migration of grain boundaries that consume the subgrains formed during cyclic heat treatments, and that the growth rate increases with increasing disorientation between the subgrains.

There is a degree of critical deformation for the dynamic recrystallization process to occur and when the degree of deformation exceeds the critical value, the recrystallized grains are gradually refined with increasing deformation ${ }^{18}$. This fact explains why the microstructure developed by the $100 \%$ HR sample has lower average grain sizes than the $30 \%$ HR sample. This indicates that for the $100 \% \mathrm{HR}$ sample the dynamic recrystallization process occurred during hot rolling.

In Figure 3 it was observed that the predominant phase in all micrographs, at room temperature, is the austenite phase. It was also verified that the non-hot rolled sample, Figure 3a, presented an average grain size around $284.15 \mu \mathrm{m}$, while the samples 100\% HR (Figure 3b) and 30\% HR (Figure 3c) presented average grains around $403.4 \mu \mathrm{m}$ and $734.17 \mu \mathrm{m}$, respectively. Thus, the lamination with a $30 \%$ reduction in the sample thickness provided a coarser microstructure with an average grain size of approximately $158 \%$ larger than the non-hot rolled samples.

Figure 4 shows the DSC curves for the $0 \% \mathrm{HR}, 30 \%$ $\mathrm{HR}$, and $100 \% \mathrm{HR}$ samples. It was possible to identify the respective start and end points of the phase transformations: $\mathrm{A}_{\mathrm{s}}$ and $\mathrm{A}_{\mathrm{f}}$ in heating, $\mathrm{M}_{\mathrm{s}}$ and $\mathrm{M}_{\mathrm{f}}$ in the cooling of specimens with and without hot rolling. Peaks corresponding to the direct martensitic (austenite $\rightarrow$ martensite) and reverse (martensite $\rightarrow$ austenite) transformations were found to shift to the left as the grain size of the tested sample decreases.

Table 1 summarizes the results of the DSC analysis, where it was observed that after lamination the samples had increased martensitic transformation temperatures. Martensitic transformation temperatures are influenced by the grain size of the austenite phase ${ }^{19,20}$. Montecinos and Cuniberti ${ }^{19}$ would evaluate the influence of austenite grain size on the $\mathrm{Cu}-\mathrm{Al}-\mathrm{Be}$ alloy $\mathrm{M}_{\mathrm{s}}$, and reported that $\mathrm{M}_{\mathrm{s}}$ decreases with grain size reduction.

In order to quantify superelasticity, induction stress and residual strain cyclic tensile tests were performed. Figure 5 shows the load-unloading assay at different temperatures for $0 \% \mathrm{HR}$ (Figure 5a), 100\% HR (Figure 5b) and 30\% HR (Figure 5c) samples. It is noteworthy that the maximum strain imposed for the $0 \%$ HR sample was only $3 \%$ due to the fragility presented by the alloy in this condition. Already the samples $100 \% \mathrm{HR}$ and $30 \% \mathrm{HR}$ were submitted to a strain amplitude of $5 \%$. 


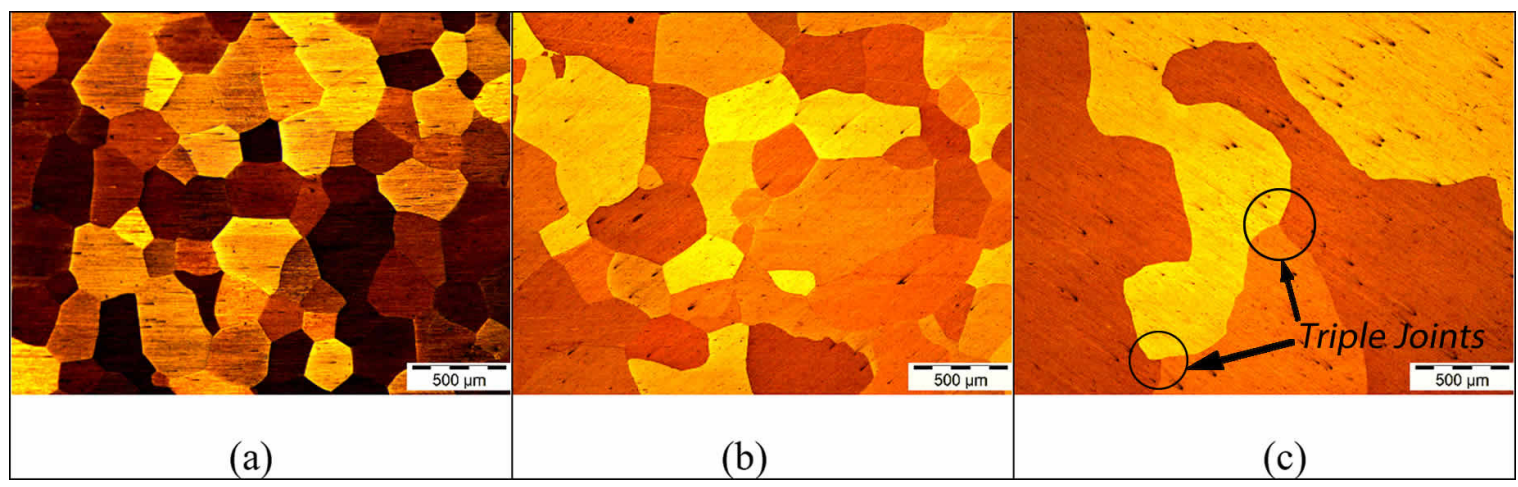

Figure 2 - Macrography of the specimens (a) $0 \% \mathrm{HR}$ (b) $100 \% \mathrm{HR}$ and (c) $30 \% \mathrm{HR}$.

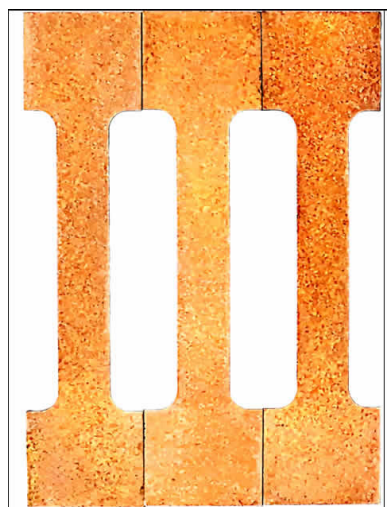

(a)

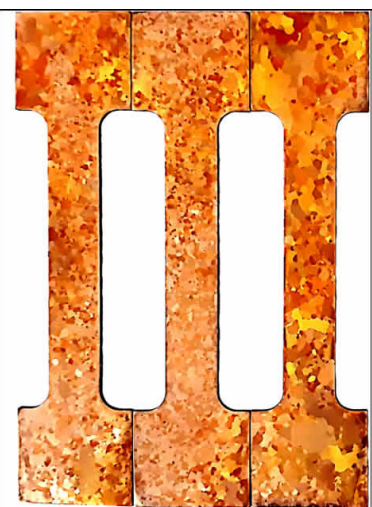

(b)

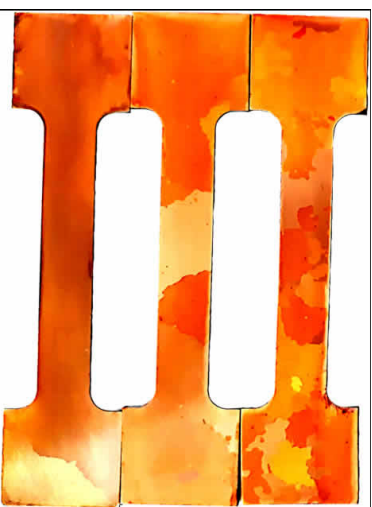

(c)

Figure 3 - Micrograph of specimens (a) non-hot rolled (b) with 100\% hot rolling and (c) with 30\% hot rolling.

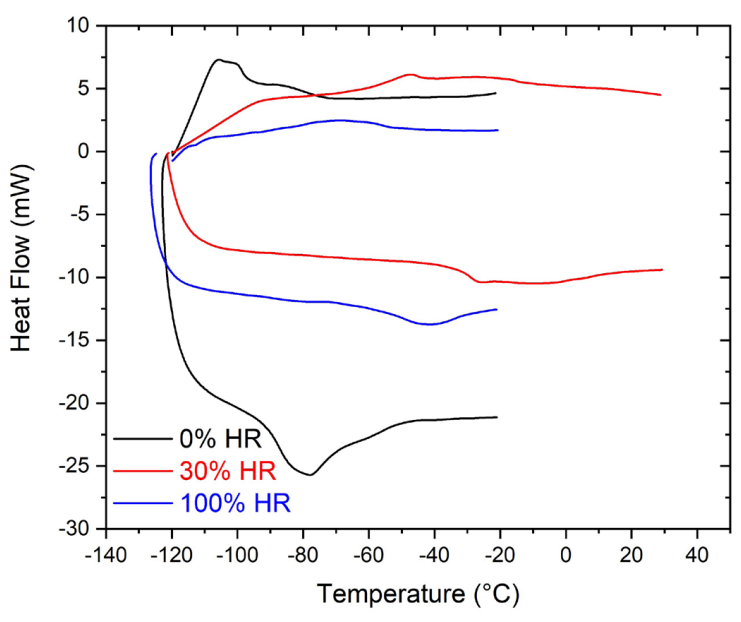

Figure 4 - DSC of Cu-Al-Be-Cr alloy alloy.

Table 1 - Cu-Al-Be-Cr alloy phase transformation temperatures.

\begin{tabular}{cccc}
\hline \multicolumn{5}{c}{ Transformation Temperature $\left({ }^{\circ} \mathbf{C}\right)$} \\
\hline $\mathbf{A}_{\mathbf{s}}$ & -91.87 & -34.37 & -63.44 \\
\hline $\mathbf{A}_{\mathbf{f}}$ & -61.87 & 10.62 & -21.87 \\
\hline $\mathbf{M}_{\mathbf{s}}$ & -88.44 & -41.25 & -49.06 \\
\hline $\mathbf{M}_{\mathbf{f}}$ & -116.87 & -62.5 & -92.50 \\
\hline
\end{tabular}

It was observed in Figure 5 that increasing the test temperature requires a higher stress to impose the same strain for both conditions ( $0 \% \mathrm{HR}, 30 \% \mathrm{HR}$ and $100 \%$ HR). For $100 \%$ HR condition (Figure $5 \mathrm{~b}$ ), for example, for a maximum deformation of $4 \%$ the corresponding stress was approximately $266.1 \mathrm{MPa}$ at a temperature of $25^{\circ} \mathrm{C}$, while at a temperature of $100{ }^{\circ} \mathrm{C}$ a stress of around $301.4 \mathrm{MPa}$ was required to impose the same deformation of $4 \%$.

In addition, it was found that samples $0 \% \mathrm{HR}$ and $100 \% \mathrm{HR}$, without abnormal grain growth, had a higher transformation slope $(\mathrm{A} \rightarrow \mathrm{M})$ than the sample with abnormal grain growth $(30 \% \mathrm{HR})$. The higher this transformation slope, the greater the stress applied to the evolution of the martensitic transformation by stress. The lower transformation slope presented by the $30 \%$ HR sample can be explained by the smaller number of triple joints presented by the sample compared to the others. According to Liu et al. ${ }^{21}$ the low energy straight grain boundary and the absence of triple grain boundary junctions in polycrystals with continuous columnar grain structure can significantly reduce the blockage of martensitic transformation at the grain boundaries.

Figure 6 shows the evolution of the induction stress of the martensitic transformation with temperature for the $0 \% \mathrm{HR}$ samples that were subjected to a maximum deformation of $3 \%$ and for the $30 \% \mathrm{HR}$ and $100 \%$ HR samples both subjected 


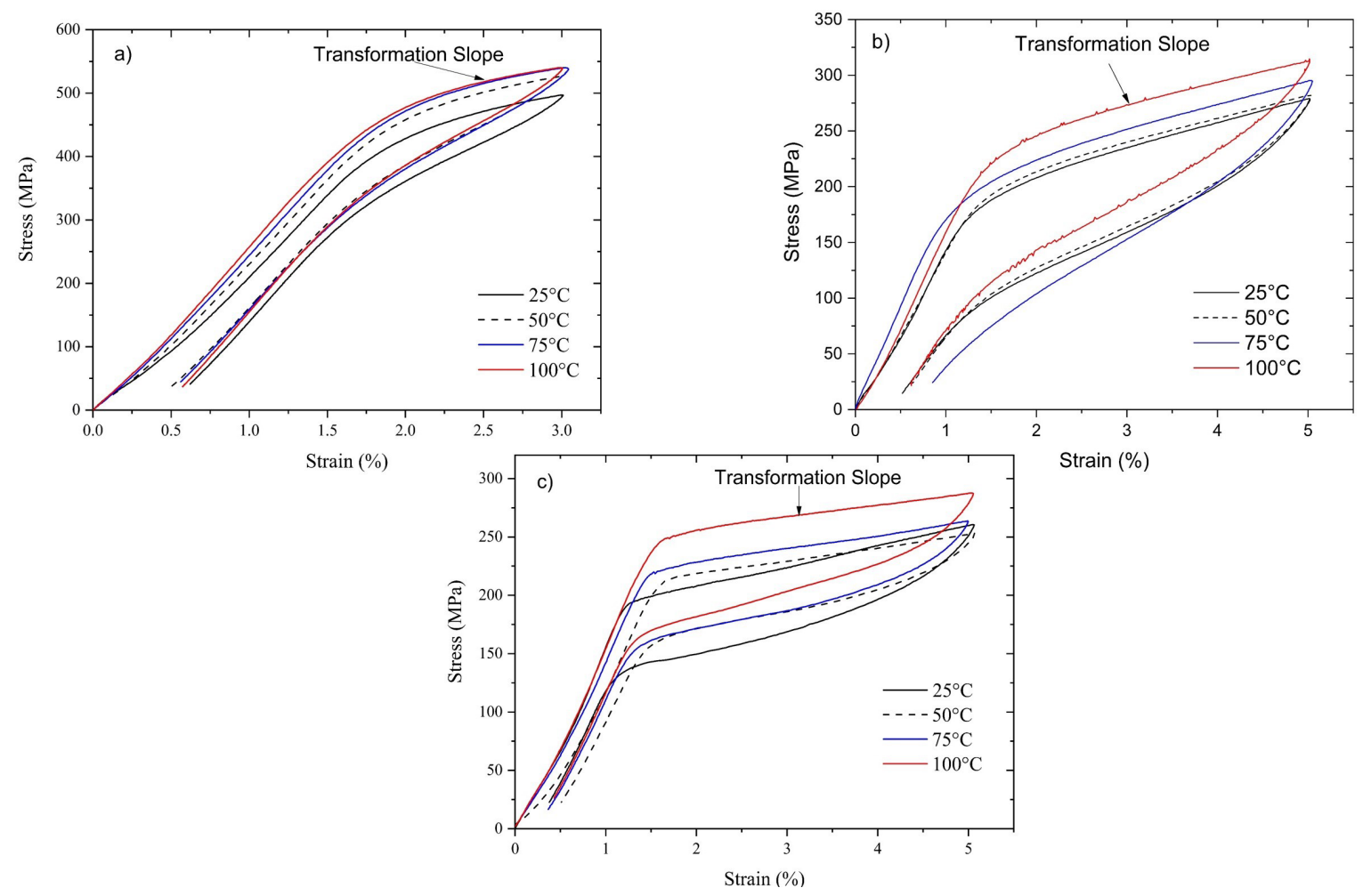

Figure 5 - Superelastic behavior at different Cu-Al-Be-Cr alloy temperatures: (a) $0 \% \mathrm{HR}$ (a) $100 \% \mathrm{HR}$ and (b) $30 \% \mathrm{HR}$.

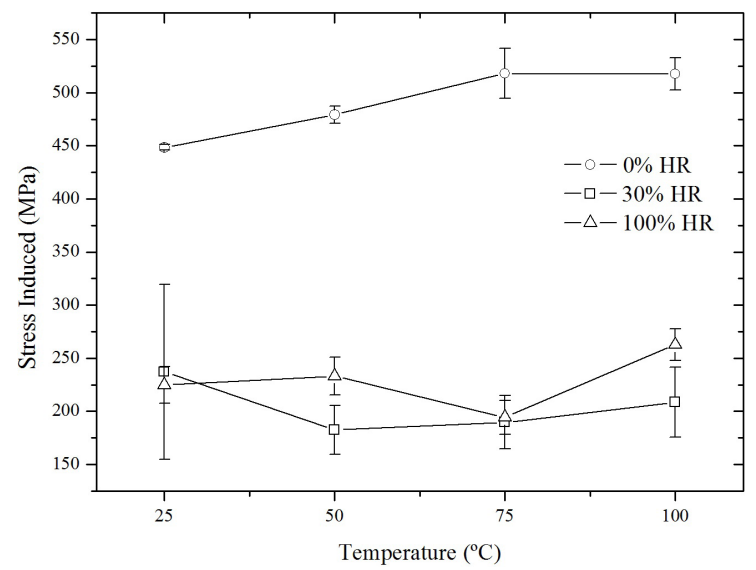

Figure 6 - Stress induced as a function of lamination degree and temperature.

to $5 \%$ deformations. The results show that the martensite induction stress for the $0 \% \mathrm{HR}$ samples was higher than those reached for the $30 \% \mathrm{HR}$ and $100 \% \mathrm{HR}$ samples for the same test temperature. This difference in induction stress is associated with the grain size of the samples. Montecinos and Cuniberti ${ }^{22}$ verified an induction stress dependence on the grain size for $\mathrm{Cu}-\mathrm{Al}-\mathrm{Be}$ alloy and reported an increase in induction stress with decreasing grain size.

Figure 7 shows the evolution of residual strain (Figure 7a) and superelasticity (Figure $7 \mathrm{~b}$ ) as a function of temperature for the $30 \% \mathrm{HR}$ and $100 \% \mathrm{HR}$ samples, both subjected to a maximum deformation of 5\%. As shown in Figure $7 \mathrm{a}$, the residual strain initially increases for the $100 \% \mathrm{HR}$ sample when the temperature increases from $25{ }^{\circ} \mathrm{C}$ to $75^{\circ} \mathrm{C}$ and decreases with increasing temperature from $75^{\circ} \mathrm{C}$ to $100{ }^{\circ} \mathrm{C}$. For the $30 \% \mathrm{HR}$ sample, there is a reduction in residual strain by increasing the test temperature from $25^{\circ} \mathrm{C}$ to $50{ }^{\circ} \mathrm{C}$, followed by a slight increase when the test temperature increases from $50{ }^{\circ} \mathrm{C}$ to $100{ }^{\circ} \mathrm{C}$. The behavior of superelasticity as a function of temperature for the $30 \%$ HR and $100 \%$ HR samples was contrary to the residual strain, as observed in Figure $7 \mathrm{~b}$.

The effect of the degree of lamination on residual strain and superelasticity can also be observed in Figures $7 \mathrm{a}$ and $7 \mathrm{~b}$, respectively. At all test temperatures, the residual strain for the $30 \%$ HR sample was lower than the $100 \%$ HR sample, while the superelasticity was higher. This behavior is associated with the abnormal grain size presented by the $30 \%$ HR sample, as well as a smaller number of triple joints.

Yamagishi et al. ${ }^{23}$ reported that the superelasticity of $\mathrm{Mg}-\mathrm{Sc}$ alloy strongly depends on the grain size and that the maximum superelasticity at room temperature was obtained on the alloy with the largest grain size. Increasing grain size decreases the number of triple joints in the alloy microstructure, and consequently improves its superelasticity due to increased deformation compatibility at grain boundaries ${ }^{24}$. 

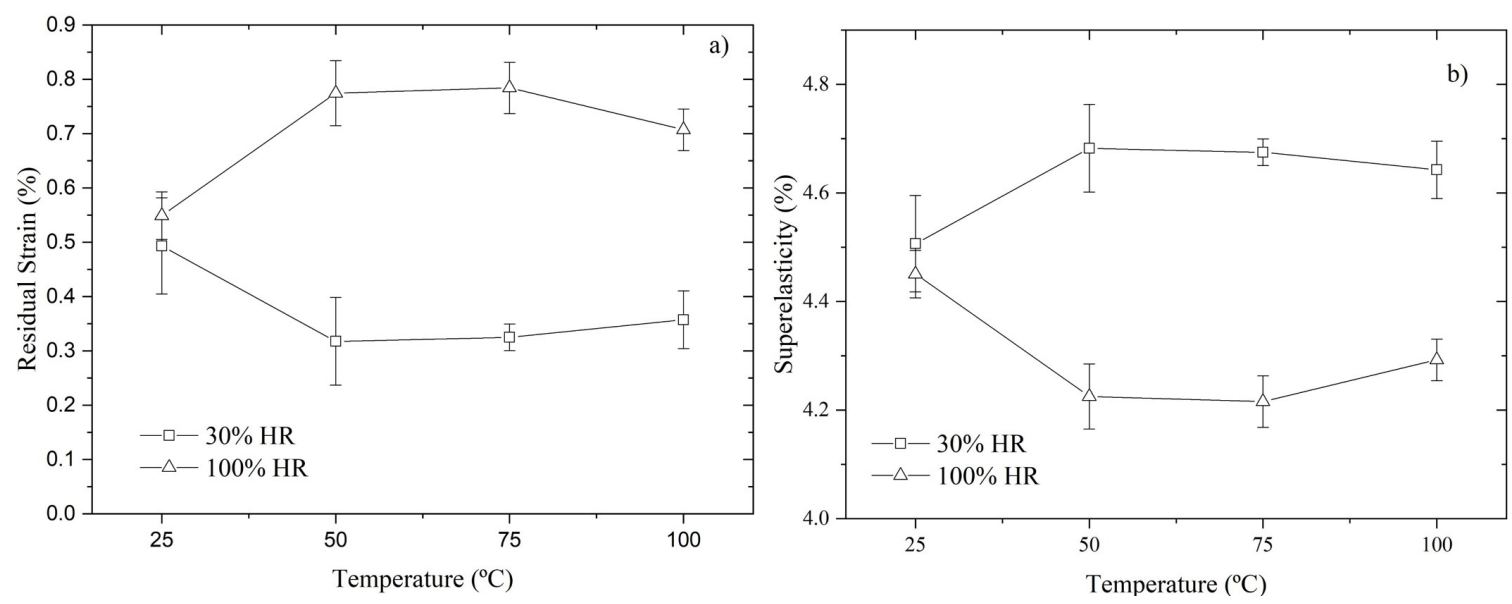

Figure 7 - a) Residual strain as a function of lamination degree and temperature. (b) Superelasticity as a function of lamination degree and temperature.

\section{Conclusion}

The influence of hot rolling on the thermomechanical and microstructural properties of a $\mathrm{Cu}-\mathrm{Al}-\mathrm{Be}-\mathrm{Cr}$ alloy was studied using DSC, optical microscopy and cyclic tensile tests at different temperatures, therefore the following conclusions were obtained.

- Hot rolling caused a rise in phase transformation temperatures. This change in temperatures is associated with increased grain size of hot rolled samples.

- $\quad$ The 30\% HR sample presented a lower transformation slope (induction of martensite by tension) than the other samples. This fact can be explained by the smaller number of triple joints presented by the sample.

- The induction stress of martensite at the same test temperature for the hot rolled samples $(30 \% \mathrm{HR}$ and $100 \% \mathrm{HR}$ ) was lower than the non-hot rolled sample $(0 \% \mathrm{HR})$. This difference in induction stress is associated with the grain size of the samples.

- $\quad$ The 30\% HR sample presented, for the same test temperature, a smaller residual strain than the one presented by the $100 \%$ HR sample, consequently a higher superelasticity. The difference in superelasticity and residual strain presented by the samples can be attributed to the abnormal grain growth of the $30 \%$ HR sample.

\section{References}

1. Oliveira JP, Zeng Z, Berveiller S, Bouscaud D, Fernandes FMB, Miranda RM, et al. Laser welding of $\mathrm{Cu}$-Al-Be shape memory alloys: microstructure and mechanical properties. Mater Des. 2018;148:145-52.

2. Narasimha GB, Murigendrappa SM. Influence of Gd on the microstructure, mechanical and shape memory properties of $\mathrm{Cu}-\mathrm{Al}-\mathrm{Be}$ polycrystalline shape memory alloy. Mater Sci Eng A. 2018;737:245-52.

3. Oliveira DF, Brito ICA, França FJC, Lima SJG, Melo TAA, Gomes RM. Assessment of pipe coupling by using the recovery of stress-induced martensites in superelastic Cu-11.8Al-0.6Be0.5Nb alloy. J Mater Eng Perform. 2017;26(5):2264-70.
4. Prashantha S, Shashidhara SM, Mallikarjun US, Shivasiddaramaiah AG. Variation in transformation temperature and shape memory effect in $\mathrm{Cu}-\mathrm{Al}-\mathrm{Be}$ shape memory alloys with the effect of quaternary elements. Appl Mech Mater. 2015;813-814:246-51.

5. Oliveira DF, Lima SJG, Brito ICA, Gomes RM, Melo TAA. Mechanical strength evaluation of a CuAlBe shape memory alloy under different thermal conditions. Mater Sci Forum. 2009;643:105-12.

6. Lanzini F, Romero R, Castro LM. Influence of Be addition on order-disorder transformations in $\beta \mathrm{Cu}-\mathrm{Al}$. Intermetallics. 2008;16(9):1090-4.

7. Montecinos S, Cuniberti A, Sepúlveda A. Grain size and pseudoelastic behaviour of a Cu-Al-Be alloy. Mater Charact. 2008;59(2):117-23.

8. Araya R, Marivil M, Mir C, Moroni O, Sepúlveda A. Temperature and grain size effects on the behavior of $\mathrm{Cu}-\mathrm{Al}-\mathrm{Be}$ SMA wires under cyclic loading. Mater Sci Eng A. 2008;496(1-2):209-13.

9. Khelfaoui F, Bellouard Y, Gessmann T, Wang X, Vlassak J, Hafez M. An investigation of the oxidation of laser and furnaceannealed sputter-deposited NiTi thin films using reflectivity measurements. In: Proceedings of the International Conference on Shape Memory and Superelastic Technologies (SMST-2004); 2004; Baden-Baden, Germany. Germany: ASM International; 2004.

10. Narendranath S, Vijay D, Basavarajappa S, Arun KV, Manjunath YS. Hot rolling and ageing effect on the pseudoelasticity behaviour of Ti-Rich TiNi shape memory alloy. J Miner Mater Charact Eng. 2010;9(4):343-51.

11. Liu J, Chen ZH, Huang H, Xie J. Microstructure and superelasticity control by rolling and heat treatment in columnar-grained $\mathrm{Cu}$ Al-Mn shape memory alloy. Mater Sci Eng A. 2017;696:315-22.

12. Chen Y, Schuh CA. Size effects in shape memory alloy microwires. Acta Mater. 2011;59(2):537-53.

13. Sutou Y, Omori T, Kainuma R, Ishida K. Grain size dependence of pseudoelasticity in polycrystalline $\mathrm{Cu}-\mathrm{Al}-\mathrm{Mn}$-based shape memory sheets. Acta Mater. 2013;61(10):3842-50.

14. Xie JX, Liu JL, Huang HY. Structure design of high-performance Cu-base shape memory alloys. Rare Met. 2015;34(9):607-24.

15. Omori T, Kusama T, Kawata S, Ohnuma I, Sutou Y, Araki $\mathrm{Y}$, et al. Abnormal grain growth induced by cyclic heat treatment. Science. 2013;341(6153):1500-2.

16. Omori T, Iwaizako H, Kainuma R. Abnormal grain growth induced by cyclic heat treatment in Fe-Mn-Al-Ni superelastic alloy. Mater Des. 2016;101:263-9. 
17. Kusama T, Omori T, Saito T, Kise S, Tanaka T, Araki Y, et al. Ultra-large single crystals by abnormal grain growth. Nat Commun. 2017;8(1):354.

18. Jiang S-Y, Zhang Y-G, Zhao Y-N. Dynamic recovery and dynamic recrystallization of NiTi shape memory alloy under hot compression deformation. Trans Nonferrous Met Soc China. 2013;23(1):140-7.

19. Montecinos S, Cuniberti A. Martensitic transformation and grain size in a $\mathrm{Cu}-\mathrm{Al}-\mathrm{Be}$ alloy. Procedia Materials Science. 2012;1:149-55.

20. Ko W-S, Maisel SB, Grabowski B, Jeon JB, Neugebauer J. Atomic scale processes of phase transformations in nanocrystalline NiTi shape-memory alloys. Acta Mater. 2017;123:90-101.
21. Liu J-L, Huang H-Y, Xie J-X. The roles of grain orientation and grain boundary characteristics in the enhanced superelasticity of $\mathrm{Cu} 71.8 \mathrm{~A} 117.8 \mathrm{Mn} 10.4$ shape memory alloys. Mater Des. 2014;64:427-33.

22. Montecinos S, Cuniberti A. Effects of grain size on plastic deformation in a $\beta$ CuAlBe shape memory alloy. Mater Sci Eng A. 2014;600:176-80.

23. Yamagishi K, Ogawa Y, Ando D, Sutou Y, Koike J. Room temperature superelasticity in a lightweight shape memory Mg alloy. Scr Mater. 2019;168:114-8.

24. Huang YJ, Liu J, Hu QD, Liu QH, Karaman I, Li JG. Applications of the directional solidification in magnetic shape memory alloys. IOP Conf Series Mater Sci Eng. 2016;117:012029. 